\title{
Gênero e sexualidades na Revista Interamericana de Psicologia: uma revisão sistemática đo
}

\author{
Beatriz de Barros Souza ${ }^{1}\left(\mathbb{D}\right.$, Eliana Rodrigues Tiago ${ }^{(0)}$, Jocilene \\ Marquesini Mongim (D), Luciana Lindinger ${ }^{-}$, \& María Antonella \\ Barone (1) ${ }^{2}$
}

Universidade Federal do Espírito Santo, Vitória, Brasil.

\begin{abstract}
RESUMO
Esta revisão sistemática sobre sexualidades e gênero abrange 80 artigos, publicados pela Revista Interamericana de Psicologia até o ano de 2019. A amostra, selecionada e classificada em três temas pelo método da análise temática, indica um aumento nessa produção a partir dos anos 1990. Nesse período, declinaram os debates sobre diferenças e papéis sexuais na amostra e cresceram as produções sobre gênero, conforme o primeiro tema. Foi possível inferir, no segundo, que esse aumento teve colaboração significativa das áreas da saúde, sendo ressaltada, ainda, a importância das estratégias de intervenção em saúde, saúde sexual e (não-) reprodutiva. A contribuição acerca de arranjos familiares e da maternidade foi apontada no terceiro tema junto com a falta de estudos centrados não apenas na cis-heteronormatividade. Por essa razão, esboçamos o nosso recorte sob a perspectiva genealógica na Psicologia da América Latina, destacando a importância de se pensar e implantar estratégias mais próximas às realidades psicossociais, éticas e culturais da região.
\end{abstract}

Palavras-chave

América Latina; gênero; psicologia; revisão; sexualidades

\begin{abstract}
This systematic review on sexualities and gender covers 80 articles, published by the Interamerican Journal of Psychology until the year 2019. The sample, selected and classified into three themes by the thematic analysis method, shows a productivity raise in this regard upon the 1990s. Ever since, debates on sexual differences and roles amidst the sample have declined while productions on gender have grown, according to the first theme. On the second, it was possible to infer that such an increase had significant collaboration from the health areas, highlighting yet the importance of some health, sexual and (non-) reproductive health intervention strategies. The contribution of family arrangements and motherhood was pointed out in the third theme along with the lack of studies that are not only centered in cis-heteronormativity. Therefore, we outline our snippet from a genealogical perspective in Latin American Psychology, highlighting the importance to think of and to implement strategies that are closer to the psychosocial, ethical and cultural realities of the region.
\end{abstract}

Keywords

Latin America; gender; psychology; review; sexualities

\footnotetext{
1 Correspondence about this article should be addressed to Beatriz de Barros Souza: biadegiz@gmail.com

2 Conflicts of Interest: The authors declare that the research was conducted in the absence of any commercial or financial relationships that could be construed as a potential conflict of interest.
} 
Gender and Sexualities in the Interamerican Journal of Psychology: a systematic review

\section{Introdução}

No século XX, sobretudo após os anos 1960, inspirados pelos movimentos sociais, feministas, gays e lésbicos, estudos sobre gênero e sexualidades começam a se emancipar das discussões sobre a essencialidade ou a reprodução. As Ciências Humanas e Sociais trouxeram, novas críticas e debates em torno das multiplicidades possíveis da expressão/exercício das sexualidades no novo contexto social (Paiva, 2008).

Nos últimos anos, as discussões acerca dos conceitos de gênero e sexualidades são observadas, por exemplo, nos estudos queer. Nesses, Butler (2013) problematiza categorias cristalizadas nos meios acadêmico e social, criticando os pares conceituais homem/mulher e masculino/feminino que, a seu ver, reproduziriam a binaridade da norma hegemônica. Para a autora, tais postulações engessam os olhares envolvendo corpo, sexo e desejo em vários níveis de expressão e articulação social. Nesse sentido, pressupostos como o binarismo de gênero e a heteronormatividade seriam postos em xeque diante de um mundo plural.

Além disso, essa categorização expressaria relações de poder pela linguagem, a qual adquire caráter político na identificação compulsória de indivíduos por Estados em termos do sexo biológico. O par sexo/gênero, por exemplo, teria servido às teorias feministas até meados de 1980, quando se começa a questionar se o sexo seria não natural, mas discursivo e cultural como o gênero, para o qual Butler (2013) propõe a ideia de efeito, expressão, performance e não mais essência, substância, atributo da pessoa, subvertendo e, assim, ressignificando esses conceitos para além do binarismo hegemônico vigente sobre corpos, sexualidades e desejos.

Em estudos recentes com epistemologias feministas na Psicologia, as análises versam, no geral, sobre como a área aborda gênero e sexualidades. Dessa maneira, enfrentam paradigmas teóricos de ênfase mais positivista e incorporam novas questões epistemológicas e metodológicas nas pesquisas. Assim, cada vez mais se questionam pretensões de neutralidade, objetividade e desinteresse da "ciência moderna", que procura "proteger os resultados da pesquisa dos valores sociais dos pesquisadores e das suas culturas" (Nogueira, 2001, p. 11), pela "perspectiva feminista na psicologia", que busca "desafiar a tendência da psicologia para aceitar a diferença" como algo natural (Nogueira, 2001, p. 23). 
Na história da Psicologia, termos e práticas foram implicados em conceitos mais amplos de saúde que incluíam direitos e deveres jurídicos, de modo que a área desenvolveu técnicas e métodos de atendimentos próprios para lidar com a saúde e o adoecimento da mente expresso no corpo (psicossomático), como medidas de "profilaxia ou prevenção das doenças mentais" (Medeiros, Bernardes \& Guareschi, 2005, p. 267).

A produção científica, após o século XVIII, apontou discursos sobre sexualidade pela Medicina e Psiquiatria como uma criação discursivo-institucional: um dispositivo, cuja função seria controlar os corpos pela normatização das práticas sexuais para definir normalidade e anormalidade, legitimando as heterossexuais, reprodutivas e monogâmicas (Foucault, 1985). Já no século XX, inspirados por movimentos sociais, estudos sobre sexualidades começam incluindo as multiplicidades da expressão/exercício das sexualidades nos novos contextos (Paiva, 2008).

$\mathrm{Na}$ Psicologia se há, por um lado, maior reconhecimento das pluralidades de práticas sexuais e usos dos corpos; por outro, são persistentes as tentativas de “. . . essencializar e naturalizar as diferenças entre homens e mulheres e reforçar estigmas e estereótipos gendrados" (Andrade \& Santos, 2013, p. 19). Em defesa de utilizar o conceito de gênero por profissionais da área como "categoria de estudo e análise profissional", Andrade e Santos (2013, p. 28) questionam seus "fazeres", suas "teorias" e seu papel, inquirindo: "De que modo temos contribuído para a redução ou o fortalecimento das negligências e discriminações no que se refere à categoria de gênero? Como a Psicologia contribui para reforçar ou quebrar estigmas e estereótipos de gênero?”.

Notando que a Psicologia pode atuar ou à disposição do sistema estatal, ou em defesa dos direitos humanos (Scarparo, Torres \& Ecker, 2014), um campo interdisciplinar, esta área é chamada a refletir acerca de sua produção e seus modos de inserir essas noções no ensino e na pesquisa (Borges et. al., 2013). Diante desse chamado, indagamos como sua produção tem refletido e se está atenta aos aportes mais recentes na área, sobretudo na América Latina, onde há traços históricos, políticos, sociais e econômicos em comum (Hur \& Lacerda Júnior, 2017).

Esses traços impactam os modos como a Psicologia compreende a realidade e produz conhecimentos para sua atuação, mesmo no Brasil (Antunes, 2012). Assim, este artigo discute parte da produção latino-americana sobre esses temas, sob uma perspectiva de inspiração genealógica (Foucault, 2001), a partir da Revista Interamericana de Psicologia (na sigla em Inglês, IJP), publicada desde 1967 pela Sociedade Interamericana de Psicologia (SIP) e uma das mais influentes e reconhecidas da região (Polanco, 2016). 
A SIP foi fundada em 1951 no IV Congresso Internacional de Saúde Mental (Cidade do México) em prol da integração entre profissionais da área em todo o continente (Angelini, 2012). Seu objetivo inicial era criar: “. . . uma estrutura institucional para a comunicação entre os países das Américas no campo da Psicologia” (Maluf, 2004, p. 324). Ao longo de todo esse período, a revista teria, ao que tudo indica, cumprido sua "missão" de promoção da Psicologia na região (Torres-Fernandez, Polanco, Pereira, Sueli-Beria \& Zapico, 2017, p. 321).

Dessa forma, pelo exposto, acreditamos que a análise facilitará a compreensão das mudanças na produção da área sobre os conceitos em foco, bem como acerca da diversidade dessa produção na América Latina, ao longo desses anos de existência da Revista.

\section{Métodos}

O presente trabalho trata-se de Revisão Sistemática de Literatura (Costa \& Zoltowski, 2014), um estudo quanti-qualitativo, para analisar artigos da Revista em foco desde a primeira edição (1967) até 2019, pela sua relevância e constância de publicação na América Latina.

\section{Coleta de dados}

Das edições da Revista disponíveis no seu site, utilizando como recorte temporal o período entre o Volume 1 (1967) e o 53, n. 02 (2019), contabilizamos 118 edições. Três-14, n. ${ }^{o} 2$ (1980), ${ }^{3}$ 22, n. ${ }^{\circ} 1 \& 2(1988)^{4}$ e 32, n. ${ }^{\circ} 1$ (1998) -, porém, estavam indisponíveis nesse site. As duas primeiras foram encontradas na Biblioteca do Instituto de Psicologia da Universidade de São Paulo (USP), e a última possuía para consulta apenas o sumário em outra base, ${ }^{5}$ sendo a única excluída da revisão.

Realizamos leitura preliminar do corpus (título, resumos e eventuais palavraschave) sob o método indutivo de identificação dos padrões dos dados (patterns within data) da análise temática (Braun \& Clarke, 2006), buscando afinidade intuitiva com o grande tema "sexualidade e gênero". Após leitura, definimos como descritores da busca:

\footnotetext{
${ }^{3}$ Link quebrado: <https://journal.sipsych.org/index.php/IJP/issue/view/55> [05/03/2020]

${ }^{4}$ Link redireciona para outra edição: 〈https://journal.sipsych.org/index.php/IJP/issue/view/65> [05/03/2020]

${ }^{5}$ Disponível: <https://dialnet.unirioja.es/revista/12854/V/32> [1\%/01/2020]
} 
mãe, gênero, masculinidade, sexo e sexua (radical de homossexual, sexualidade, outros), traduzidos para três idiomas (Português, Inglês e Espanhol).

\section{Definição da Amostra}

Optamos por excluir artigos que não continham os descritores no título, resumo e/ou palavras-chave (após 2000), mesmo que dialogassem com o grande tema. Além disso, foram selecionados apenas artigos, sendo excluídas resenhas e outros gêneros textuais.

Definidos os descritores, iniciamos a revisão sistemática estrita dos 1145 artigos da Revista. Para este fim, estabelecemos como critérios de inclusão que os descritores deveriam estar: a) no título, resumo e/ou palavras-chave; b) em ao menos um idioma da Revista.

Essa busca (Etapa 1 da análise temática) resultou em 224 artigos, submetidos a uma segunda, sob os mesmos descritores, para checar os critérios de exclusão: a) contexto não se refere à realidade latino-americana; b) descritor caracteriza a amostra, mas não guarda relação com o tema estudado; c) análise não se refere ao grande tema.

Após essa seleção (Etapa 2), os 80 artigos restantes tiveram revistos o título, resumo, palavras-chave e resultados para a codificação temática (Etapa 3), sendo divididos por década e identificados os seus subtemas. Na etapa seguinte, a partir desses subtemas, definimos três temas: 1) O conceito de gênero como estruturante das relações psicossociais; 2) Gênero e sexualidades: olhares sob a perspectiva da saúde; 3) Família, espaço de possibilidades e de (re)produção de relações de gênero.

Por último, os 80 artigos foram lidos na íntegra por todas as autoras e classificados por afinidade em um dos três temas. Dos artigos com classificação divergente entre as autoras e/ou que caberiam em mais de um tema ao mesmo tempo, foi escolhida coletivamente a melhor composição, a partir de aspectos quanti e qualitativos (Braun \& Clarke, 2006). Assim, todos os artigos passaram por avaliação coletiva para obter a classificação indicada nos resultados.

\section{Análise temática}

Para a análise, uma vez definidos dentro de cada tema, os artigos foram listados nos quadros dos subtemas em ordem cronológica. Cada quadro foi seguido por breve descrição dos artigos, sendo destacada a sua relação com o subtema, o tema e a literatura. 
Essa descrição breve, guiada tematicamente, permitiu uma discussão do modo como os tópicos foram investigados em cada época na Revista. Cada subtema, portanto, traz as suas considerações acerca de uma questão central para o tema a que pertence à luz da literatura, a qual, por sua vez, indica os rumos dessas pesquisas.

Dado o escopo desta revisão, as discussões com a literatura em cada tema não tiveram, certamente, a profundidade desejada. Esperamos, todavia, que os resultados e a sua discussão a seguir ressaltem pontos relevantes para estudos futuros.

\section{Resultados}

Após a análise dos subtemas, os artigos foram codificados em três temas, como visto anteriormente, resultando no seguinte quantitativo: a) 35 artigos, no Tema 1; b) 25 artigos, no Tema 2; c) 20 artigos, no Tema 3. O primeiro tema aborda tópicos como diferenças culturais, papéis sociais e relações psicossociais de gênero, diferenças culturais e sexuais, papéis sexuais, movimentos sociais, identidade sexual, feminilidades, masculinidades, violências e estereótipos de gênero. No segundo, há estudos do comportamento sexual, prevenção de enfermidades e HIV/AIDS. O terceiro, com foco na família, fala de maternidade, paternidade, desenvolvimento infantil, violência doméstica e processo terapêutico familiar. Como primeiro achado, a ocorrência dos descritores nos 80 artigos selecionados consta da Figura 1.

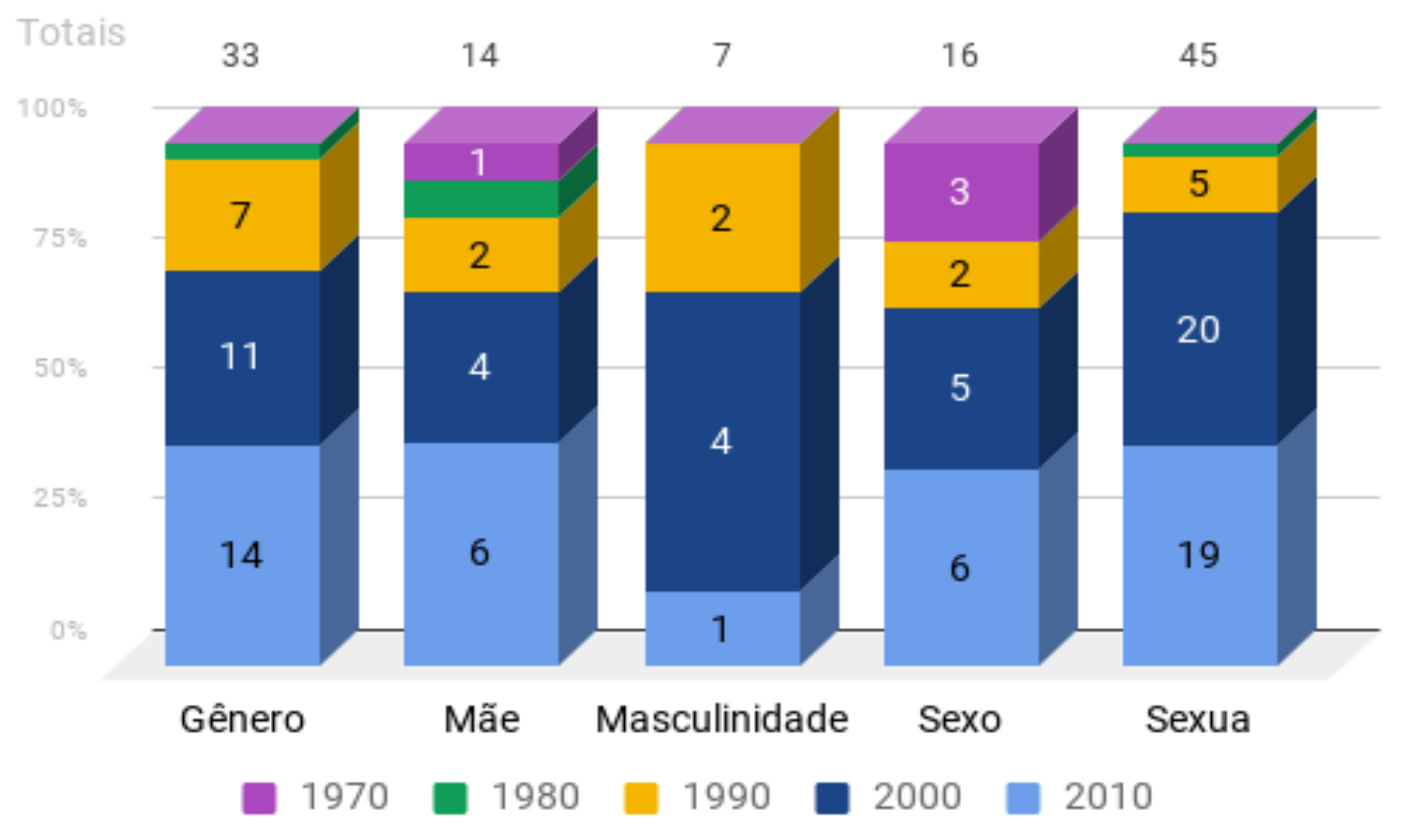

Figura 1. Distribuição dos descritores por década 
Na Figura 2, observa-se mais artigos a partir dos anos 1990 e sua concentração nas duas últimas décadas, sobretudo a de 2000, com os descritores sexo e sexua em quase todas as décadas. Utilizado para contemplar diferentes léxicos, sexua teve maior incidência (45 vezes) entre os descritores, sobretudo nas duas últimas décadas (43,3\% do período). A produção em torno do descritor gênero também foi alta nesse período, em especial na última década (30,4\% da produção), com aumento significativo a partir de sua emergência nos anos 1990.

De menor incidência, o descritor masculinidade só emerge na amostra a partir de 1990, concentrado nos anos 2000 (57,1\%). Como nos demais, a taxa de mãe obteve um aumento ao fim do século XX, com pico $(42,8 \%)$ em 2010. Foi a segunda menor ocorrência $(12,2 \%)$ entre todos os descritores, perdendo apenas para masculinidade $(6,1 \%)$. Note-se que os anos 2000 são responsáveis por 38,2\% e a década de 2010 por $40 \%$ dos descritores, o que instiga a investigar quais fenômenos aumentaram o interesse por tais temas nas duas últimas décadas.

$\mathrm{Na}$ amostra, a distribuição por década após a codificação temática segue no Figura 2.

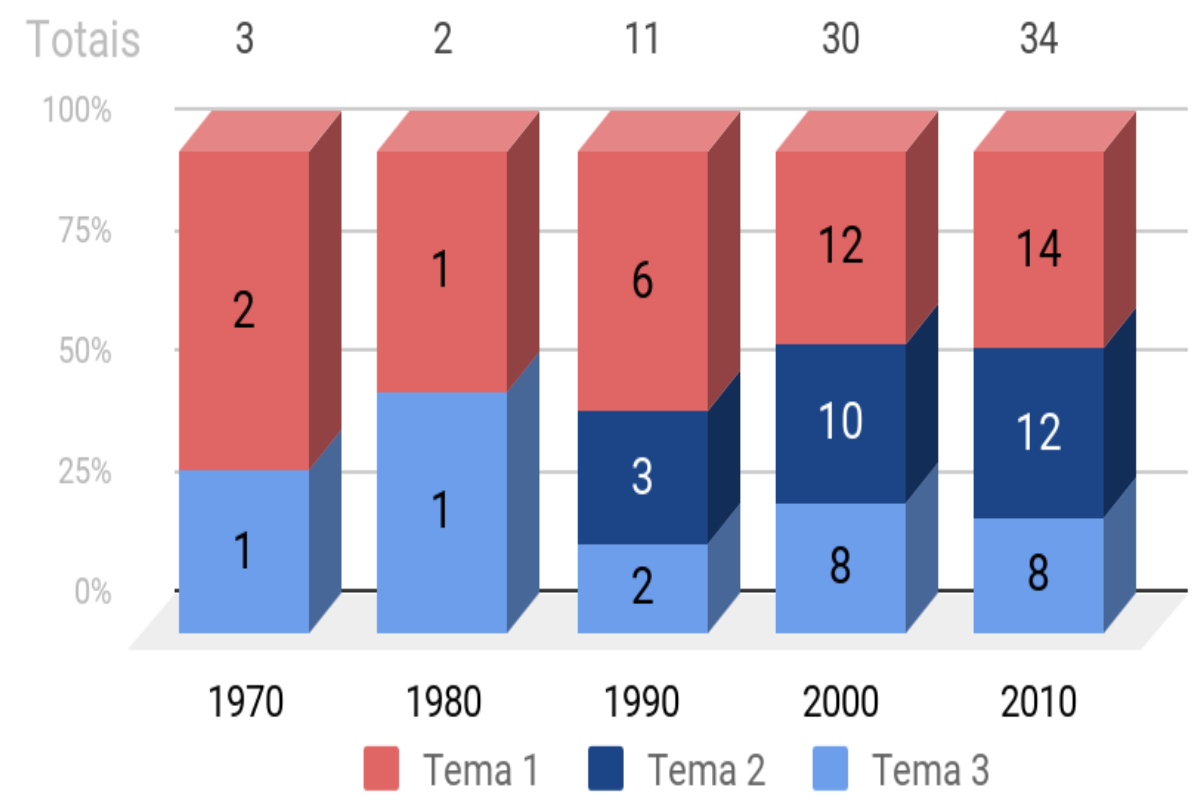

Figura 2. Codificação temática por década

Quanto à produtividade por década, não houve artigos nos anos 1960, tendo apenas cinco artigos nos Temas 1 e 3 de 1970 a 1980. O Tema 2, mais afim às questões de saúde e sexualidade, emerge a partir de 1990. Também a partir de 1990, entraram questões abordadas nos outros dois, notadamente no Tema 3, que explora relações de 
gênero e família. Nas décadas de 2000 e 2010, houve quantidade similar de artigos nos temas 1 e 2 , tendo o Tema 1 cerca de $43,8 \%$ do total. No geral, os temas, sobretudo 2 e 3 , têm uma produção crescente, sugerindo tendências para a próxima década.

Com relação ao gênero dos autores, atribuído a partir do nome social e da consulta eventual às bases curriculares, notamos o interesse nos temas abordados e uma produção acadêmica entre as pesquisadoras, sobretudo a partir dos anos 1990, como se verá adiante.

\section{Discussão}

Para a maior ocorrência dos temas de gênero e sexualidades após 1990, a literatura apresenta hipóteses relacionadas a movimentos feministas ocidentais (Scott, 1995) e à criação de grupos de estudos, como no Brasil (Rago, 1998). Nas décadas anteriores, no entanto, há debates que podem ser considerados precedentes para essa discussão. Considerando, então, todos os saberes "psi" da Revista, comentaremos adiante esses artigos à luz da literatura atual.

\section{O conceito de gênero como estruturante das relações psicossociais (Tema 1)}

Este Tema possui o maior número (35) de artigos e perpassa todas as décadas desta revisão, exceto, os anos 1960. Para os propósitos desta revisão, os artigos foram divididos em quatro subtemas e referenciados nos respectivos quadros de conteúdo.

Remontando aos anos 1970, o subtema Papéis sexuais e de gênero consiste no único do Tema 1 anterior aos anos 1990. Apesar da variedade de assuntos e métodos, o foco é sobre "diferenças sexuais" e "papéis sexuais" nos artigos de 1970 e 1980. A emergência do gênero como categoria de análise nos anos 1990 completa os dez artigos desse subtema (tabela 1).

Nos anos 1970, crianças participaram nos dois artigos elencados. No primeiro, um estudo psicométrico comparou habilidades cognitivas estadunidenses e mexicanas (IJP, 1970). No segundo, crianças brasileiras auxiliaram estudo sobre a relação entre sexo, classe, desempenho e atração por brinquedos (IJP, 1977). Na década seguinte, estudantes da Costa Rica participaram de um estudo sobre papéis sexuais nos EUA (IJP, 1988).

Na década de 1990, encontramos mais quatro artigos nesse subtema: um sobre papéis sexuais e sua relação com a classe social no México (IJP, 1994); um inventário de respostas a estímulos sexuais e sua relação com o grau de identificação do participante com certos papéis sexuais e o seu sexo (IJP, 1995); um sobre diferenças de gênero e 
origem nos sonhos de participantes de Argentina, Brasil e EUA (IJP, 1998) e um sobre no raciocínio moral pró-social de crianças e adolescentes nos EUA e no Brasil quanto à nacionalidade e ao gênero (IJP, 1999). Esses primeiros usos de gênero, por vezes, ocorrem como sinônimo de sexo, tal como utilizado nas décadas anteriores.

Tabela 1.

Subtema Papéis sexuais e de gênero (Tema 1)

\begin{tabular}{ccccc}
\hline \multicolumn{2}{c}{$\begin{array}{c}\text { Revista } \\
\text { (IJP) }\end{array}$} & Pessoa(s) autora(s) & $\begin{array}{c}\text { Assunto(s) } \\
\text { chave }\end{array}$ & $\begin{array}{c}\text { País(es) } \\
\text { participante(s) }\end{array}$ \\
\hline Ano & v. (n) & Mebane \& Johnson & Diferenças sexuais & EUA, México \\
1970 & $4(3)$ & Plencar, Alvim \& Matias & Páis sexuais & Brasil (BRA) \\
1977 & $11(2)$ & Kashak \& Sharatt & Papéis sexuais & Costa Rica \\
1988 & $\begin{array}{c}22(1 \& 2 \\
\text { (1) }\end{array}$ & Acuña, Bruner \& Avila & Papéis sexuais & México \\
1994 & $28(2)$ & De Souza \& Hutz & Papéis sexuais & Brasil (BRA) \\
1995 & $29(1)$ & Krippner, Winkler, Rochlen \& Yashar & Diferenças de gênero & EUA, Argentina \\
1998 & $32(2)$ & Carlo, Roesch \& Koller & Papéis de gênero & Argentina, BRA, EUA \\
1999 & $33(1)$ & Baldwin \& De Souza & Papéis de gênero & Brasil \\
& & Acuña \& Bruner & Papéis sexuais & México \\
\hline
\end{tabular}

No início do século, ainda há artigos sobre papéis sexuais, como o estudo comparando seus estereótipos no México e nos EUA (IJP, 2001) ou o estudo psicométrico que aplicou inventário desses papéis no Chile (IJP, 2009). Ainda assim, emergem fatores, como história, trabalho/economia, religião e outros, em um ensaio teórico sobre papéis de gênero e a relação com o "marianismo" no Brasil (IJP, 2001). Acerca do fim desse subtema na década passada, Connell (1995, p. 27) afirma que os conceitos de papéis sexuais nas Ciências Sociais dificultam compreender relações de gênero como relações de poder, podendo “. . . minimizar a violência, suprimir a questão da coerção, fazendo uma suposição ampla de consentimento".

Já no subtema Relações e identidades sexuais e de gênero, emergente após 1990, há oito artigos sobre relações de gênero, identidades sexuais e de gênero, além de sexismos, incluindo atitudes, preconceitos e estereótipos de gênero e sexualidades (Tabela 2). 
Tabela 2.

Subtema Relações e identidades sexuais e de gênero (Tema 1)

\begin{tabular}{|c|c|c|c|c|}
\hline \multicolumn{2}{|c|}{$\begin{array}{c}\text { Revista } \\
\text { (IJP) }\end{array}$} & \multirow[t]{2}{*}{ Pessoa(s) autora(s) } & \multirow{2}{*}{$\begin{array}{l}\text { Assunto(s) } \\
\text { chave }\end{array}$} & \multirow{2}{*}{$\begin{array}{c}\text { País(es) } \\
\text { participante(s) }\end{array}$} \\
\hline & v. (n) & & & \\
\hline 1998 & $32(2)$ & Keating \& Kurtz-Costes & $\begin{array}{l}\text { Relações de gênero } \\
\text { (poder) }\end{array}$ & Equador \\
\hline 2006 & $40(1)$ & Toro-Alfonso, Díaz, Andújar-Bello \& N.-Rosa & Identidade sexual & Porto Rico \\
\hline 2009 & $43(2)$ & Sánchez & Identidade de gênero & México \\
\hline 2011 & $45(2)$ & Smith-Castro \& Molina-Delgado & Sexismos (Homofobia) & Costa Rica \\
\hline 2014 & $48(3)$ & Chaigneau \& Rosenbluth & Sexismos (Misoginia) & Chile \\
\hline \multirow{2}{*}{2018} & $52(1)$ & Nava-Reyes, Rojas-Solís, Amador \& Quintero & Sexismos (Misoginia) & México \\
\hline & $52(2)$ & Codas & Sexismos (LGBTfobia) & Paraguai \\
\hline 2019 & $53(1)$ & $\begin{array}{c}\text { Smith-Castro, Montero-Rojas, Moreira-Mora \& } \\
\text { Zamora-Araya }\end{array}$ & Sexismos (Misoginia) & Costa Rica \\
\hline
\end{tabular}

Nesse sentido, aos poucos, a categoria de gênero ganha uma conotação mais ampla, no que destacamos um artigo sobre crenças de mulheres acerca de oportunidades na família, na escola e no trabalho, sendo apontado que o tradicional papel masculino predominaria ainda no Equador (IJP, 1998). Nesse subtema, há ainda artigos sobre identidades sexuais e de gênero.

Quanto a essas identidades, importa destacar que há diferentes siglas para designar os grupos que assim se identificam, como GLS (gays, lésbicas e simpatizantes), GLBT (gays, lésbicas, bissexuais e travestis), entre outras. Embora respeitada na citação indireta, a presente revisão utiliza a sigla LGBTT+ (lésbicas, gays, bissexuais, travestis, transexuais e outros) como termo guarda-chuva de marcadores sociais da diferença em alguns setores da sociedade, reconhecendo ainda o limite à representação de vivências e experiências do símbolo + .

$\mathrm{Na}$ amostra, este debate emerge com um artigo sobre adolescentes gays e bissexuais em Porto Rico (IJP, 2006) e em outro, sobre a construção da identidade de gênero e descobertas teóricas no contexto mexicano (IJP, 2009). Quanto a sexismos, houve trabalhos sobre homofobia em razão da união civil na Costa Rica (IJP, 2011) e contra a população LGBTI+ no Paraguai (IJP, 2018). Estereótipos de gênero e ideologias sexistas em relação às mulheres, por sua vez, foram objeto de estudos sobre o mercado de trabalho no Chile (IJP, 2014) e sobre o desempenho das mulheres na Matemática na Costa Rica (IJP, 2019).

Por sua vez, o subtema Masculinidades, práticas sexuais e de gênero elenca dez artigos a partir dos anos 1990 (Tabela 3). 
Tabela 3.

Subtema Masculinidades, práticas sexuais e de gênero (Tema 1)

\begin{tabular}{|c|c|c|c|c|}
\hline \multicolumn{2}{|c|}{$\begin{array}{l}\text { Revista } \\
\text { (IJP) }\end{array}$} & \multirow[t]{2}{*}{ Pessoa(s) autora(s) } & \multirow{2}{*}{$\begin{array}{l}\text { Assunto(s) } \\
\text { chave }\end{array}$} & \multirow{2}{*}{$\begin{array}{c}\text { País(es) } \\
\text { participante(s) }\end{array}$} \\
\hline Ano & v. (n) & & & \\
\hline 1992 & $26(1)$ & Medina & Masculinidades, Poder & Porto Rico \\
\hline 2004 & $38(2)$ & Diaz-Loving, Sánchez \& Aragón & Masculinidade, Feminilidade & México \\
\hline \multirow{3}{*}{2008} & \multirow{2}{*}{$42(1)$} & García-Campos & Masculinidades, Papéis sexuais & México \\
\hline & & Cardoso & Orientação sexual, Motricidade & Brasil (BRA) \\
\hline & $42(2)$ & De La Rubia & $\begin{array}{c}\text { Práticas sexuais (satisfação } \\
\text { sexual) }\end{array}$ & México \\
\hline \multirow{4}{*}{2011} & $45(1)$ & Rodríguez \& Alfonso & Sexualidade, Papéis de gênero & Porto Rico \\
\hline & $4 J(1)$ & Rubia & Práticas sexuais (masturbação) & México \\
\hline & $45(2)$ & Alvarado, Borjas e Ortega & $\begin{array}{c}\text { Práticas sexuais (satisfação } \\
\text { sexual) }\end{array}$ & México \\
\hline & $45(3)$ & Rodríguez e Loving & $\begin{array}{c}\text { Práticas sexuais (motivação } \\
\text { sexual) }\end{array}$ & México \\
\hline 2016 & $50(2)$ & Gutiérrez & Sexualidades, Homens transexuais & Chile \\
\hline
\end{tabular}

Dessa forma, o primeiro assunto deste subtema surge após 1990 na amostra, com um estudo teórico sobre como relações de gênero envolvem relações de poder nos grupos com homens (IJP, 1992). Esse achado está consoante com Medrado e Lyra (2008) e Souza (2009), no que tange ao aumento da produção, e com Medrado e Lyra (2012) quanto à influência dos movimentos feministas e LGBTT+ nesse aumento.

No geral, esses estudos ainda não se dissociam daqueles sobre papéis sexuais já vistos. Assim, nos anos 2000, um artigo busca um instrumento etnopsicologicamente válido dos atributos de masculinidade e feminilidade do povo mexicano (IJP, 2004) e outro aborda as variáveis sociodemográficas na expressão dos papéis sexuais no México (IJP, 2008). Quanto às práticas sexuais, lembramos que os descritores sexo e sexua estavam em quase todas as décadas, sobretudo após os anos 2000, como indicam os outros artigos do subtema. Destes, o produzido no Chile (IJP, 2016) investigou os sentidos das sexualidades de homens trans para além dos processos patologizantes.

Relacionando diferentes grupos a conceitos de violências, relações de gênero e poder (Saffioti, 2001; Strey, 2004), há sete artigos no subtema Violências e Resistências (Tabela 4). 
Tabela 4.

Subtema Violências e Resistências (Tema 1)

\begin{tabular}{|c|c|c|c|c|}
\hline \multicolumn{2}{|c|}{$\begin{array}{c}\text { Revista } \\
\text { (IJP) }\end{array}$} & \multirow[t]{2}{*}{ Pessoa(s) autora(s) } & \multirow{2}{*}{$\begin{array}{l}\text { Assunto(s) } \\
\text { chave }\end{array}$} & \multirow{2}{*}{$\begin{array}{c}\text { País(es) } \\
\text { participante(s) }\end{array}$} \\
\hline Ano & v. (n) & & & \\
\hline 2003 & $37(1)$ & Larrañaga \& Gutiérrez & Violências (Abuso infantil) & Chile \\
\hline 2004 & $38(1)$ & De Souza, Pryor, Ribeiro, Mello e Camino & Violências (Assédio sexual) & $\begin{array}{l}\text { EUA, Brasil } \\
\text { (BRA) }\end{array}$ \\
\hline 2007 & $41(3)$ & $\begin{array}{l}\text { Gianordoli-Nascimento, Trindade \& } \\
\text { Santos }\end{array}$ & Resistências (Mulheres) & Brasil (BRA) \\
\hline 2008 & $42(2)$ & Costa, Machado e Prado & Resistências (LGBT+) & Brasil (BRA) \\
\hline \multirow{2}{*}{2010} & $44(1)$ & Sanfelice \& De Antoni & Violências (Abuso infantil) & Brasil (BRA) \\
\hline & $44(2)$ & Romero, Pick, Corria \& Givaudan & Violências (Prevenção) & México \\
\hline 2019 & $53(2)$ & Lenta, Longo \& Zaldúa & Resistências (Mulheres) & Argentina \\
\hline
\end{tabular}

Existe uma ligação nefasta entre violência e questões de gênero e sexualidades, uma vez que aquela desqualifica as identidades de gênero e de orientação sexual, enquanto lutas por direitos denunciam e questionam padrões heteronormativos (Paula, Porto, \& Carvalho, 2019). Notamos que poder não é posse, e sim um exercício cujas relações "funcionam como rede de dispositivos ou mecanismos a que nada ou ninguém escapa, a que não existe exterior possível, limites ou fronteiras" (Foucault, 2001, p. xiv). Dessa forma, na imanência dessas relações também seriam produzidos processos de resistência (Foucault, 2001).

Acerca das violências, temos: um artigo sobre o abuso sexual na infância entre universitários chilenos (IJP, 2003); um artigo com estudo de casos múltiplos sobre percepções de abusadores sexuais de crianças (privados de liberdade) acerca da própria sexualidade (IJP, 2010); uma pesquisa-ação sobre violências de gênero contra mulheres no trabalho (IJP, 2019). Este último fala também de resistências, uma vez que foi estudada a participação social e as estratégias de enfrentamento a essas violências.

Quanto às resistências, dois artigos focaram movimentos sociais e relações de gênero. Do primeiro, participaram mulheres de oposição política ao regime militar no Brasil (1964 a 1985) com entrevistas sobre aspectos psicossociais nos processos identitários das suas relações de gênero e militância contra esse regime (IJP, 2007). No segundo, esses aspectos foram investigados como impedimentos e possibilidades à participação política no movimento GLBT de Belo Horizonte, Minas Gerais (IJP, 2008). 
Nesse subtema, houve grande presença de trabalhos sobre a violência de gênero contra crianças, adolescentes e mulheres, mas poucos que escapassem a uma perspectiva heteronormativa e binária da análise, que também aparecem nos outros Temas.

\section{Gênero e sexualidades: olhares sob a perspectiva da saúde (Tema 2)}

Gênero e sexualidades são aspectos interligados ao conceito de saúde, sujeitos a normas e olhares de diferentes instituições e áreas que compõem esse campo de saber, como a psicologia. Para esse tema, utilizamos o conceito da OMS (2006, p. 5) de "saúde sexual”, que se refere não apenas a princípios biológicos e fisiológicos, à classificação de doenças e ao tratamento de sintomas, físicos ou mentais, como também a um "bem-estar físico, emocional, mental e social em relação à sexualidade".

Nesse sentido, os artigos desse tema foram agrupados em dois subtemas. Em Saúde mental, patologização e diagnósticos de gênero, sete artigos, no geral, avaliaram transtornos mentais à luz de questões de gênero, fatores culturais e sociais (Tabela 5).

Tabela 5.

Subtema Saúde mental, patologização e diagnósticos de gênero (Tema 2)

\begin{tabular}{|c|c|c|c|c|}
\hline \multicolumn{2}{|c|}{ Revista (IJP) } & \multirow{2}{*}{ Pessoa(s) autora(s) } & \multirow{2}{*}{$\begin{array}{l}\text { Assunto(s) } \\
\text { chave }\end{array}$} & \multirow{2}{*}{$\begin{array}{c}\text { País(es) } \\
\text { participante(s) }\end{array}$} \\
\hline Ano & v. (n) & & & \\
\hline 2008 & $42(3)$ & Borges e Dell'Aglio & $\begin{array}{l}\text { Abuso sexual infantil } \\
\text { (indicadores de risco) }\end{array}$ & Brasil (BRA) \\
\hline 2009 & $43(1)$ & Narvaz e Oliveira & $\begin{array}{c}\text { Abuso sexual (transtornos } \\
\text { alimentares) }\end{array}$ & Brasil (BRA) \\
\hline \multirow[t]{2}{*}{2010} & $44(2)$ & Toro-Alfonso, Nieves e Borreo & $\begin{array}{l}\text { Transtornos alimentares } \\
\text { (masculinidades) }\end{array}$ & Porto Rico \\
\hline & & De la Rubia & Abuso sexual (fantasias) & México \\
\hline 2013 & $47(1)$ & $\begin{array}{c}\text { Raffaelli, Andrade, Poppe, Sanchez-Armass, } \\
\text { Vidal e Garcia }\end{array}$ & Depressão e gênero & México \\
\hline 2015 & $49(2)$ & Vuyk & Depressão e gênero & Paraguai \\
\hline 2017 & $51(3)$ & Cruz, Ortiz, Hernández-Martínez e Sánchez & Depressão e gênero & México \\
\hline
\end{tabular}

$\mathrm{Na}$ literatura, temos a hipótese de que a expressão do adoecer em determinados corpos pode resultar de produções sociais, culturais e morais, inclusive dos "fenômenos psicológicos" (Medeiros, Bernardes \& Guareschi, 2005, p. 268), que tanto concernem a psicologia e a saúde em geral. Nesse subtema, artigos abordam "doenças mentais", sobre o que se deve cuidar para não reincidir, da medicalização, em novas formas de controle social dos fenômenos humanos existenciais, ou seja, não apenas neurofisiológicos (Campos \& Zanello, 2016; Zanello \& Bukowitz, 2011). 
Nesse sentido, surgem, na amostra, dois artigos sobre abuso sexual infantil no Brasil. O primeiro afirma que esse abuso impacta no desenvolvimento infantil e acarreta sintomas emocionais e comportamentais colaterais em meninas, como o Transtorno de Estresse Pós-Traumático (IJP, 2008). O segundo, por revisão de literatura, conclui que esse abuso seria fator de risco para transtornos alimentares, notando que a correlação destes com o gênero seria multifatorial, envolvendo questões estéticas e sociais (IJP, 2009).

Posto que esses artigos reiterem maior ocorrência da depressão em mulheres, notamos que esta forma de adoecer possui vínculo com as relações de poder nos corpos, de modo que “. . . seus comportamentos e sentimentos deveriam ser compreendidos mais como respostas plausíveis, quando contextualizados, do que como sintomas psiquiátricos" (Campos \& Zanello, 2016, p. 113). O saber psiquiátrico, por vezes, considera o sintoma e o diagnóstico de experiências como algo inerente (e não como produção normativa) nos corpos à margem da representatividade social e econômica (Campos \& Zanello, 2016; Zanello \& Bukowitz, 2011).

Em seguida, emerge outra pesquisa sobre transtornos alimentares, desta vez, com foco nos corpos masculinos em Porto Rico (IJP, 2010). Considerando a masculinidade hegemônica resultante de relações de poder que servem ao patriarcado, esse estudo vê o sofrimento desses corpos no aumento desses transtornos, sobretudo entre homossexuais, para os quais cobranças sociais por certo tipo físico seriam um fator adicional de risco.

Novamente sobre abusos sexuais, estudo no México, embora sem correlação estatisticamente significativa entre tais abusos e fantasias sexuais, indica que as relativas à promiscuidade, sadomasoquismo e homossexualidade seriam maiores em vítimas femininas desses abusos (IJP, 2010). Lembramos, que tais dados carecem de maior validação antes de serem indícios de propensão a doenças mentais, um campo produzido e não descoberto na saúde, com elevado caráter de controle social e moral (Foucault, 1982).

Quanto à depressão, o artigo com estudantes superdotados no Paraguai não distinguiu a percepção do perfeccionismo, que seria alto para ambos os gêneros, mas sim o escore de depressão, maior entre meninas (IJP, 2015). Com público mais amplo, dois estudos no México indicam que mulheres teriam duas vezes mais quadro depressivo que homens, identificando diferentes preditores (bebidas alcoólicas para homens; pensamento ruminativo e tabagismo para mulheres) dessa ocorrência (IJP, 2013; IJP, 2017). Referem, 
ainda, a fatores sociais e culturais, e sugerem que se inclua o processo de socialização por gênero nas análises.

As diferenças com que mulheres e homens experienciam a existência e os sofrimentos subjetivos foram, certo modo, investigadas na Revista. No geral, contudo, essas diferenças foram invisibilizadas no processo diagnóstico e na prática clínica cotidiana, como costuma acontecer área (Campos \& Zanello, 2016; Souza, 2012; Zanello \& Bukowitz, 2011). Além da invisibilidade histórica e marginal dos corpos femininos, denunciadas por movimentos feministas e LGBTT+, são corpos, como os nãonormativos, sujeitos historicamente a violências para controle e manutenção do poder masculino em sociedades patriarcais e heteronormativas (Gomes, Murta, Facchini \& Meneghel, 2018).

A falta de uma compreensão mais ampla da saúde pode colaborar na construção de um normal e um desvio/patológico na saúde como padrões que, todavia, são sociais e culturais e, por conseguinte, podem se alterar no tempo (Souza, 2012; Zanello \& Bukowitz, 2011). Dessa forma, seria necessário subverter a lógica dos diagnósticos, ainda persistente nesses saberes.

Pensar o sofrimento psíquico, portanto, extrapola o discurso biomédico e leva a pensar fatores sóciopolítico-econômico-culturais, como as relações de gênero, que nos constituem. Assim, introduzimos o subtema chamado Saúde sexual e (não) reprodutiva: produção de saberes e subjetividades. A partir da epidemia de HIV/AIDS nos anos 1980, de fato, houve um salto na produção, em Saúde relativa a esse vírus (Tabela 6).

Nos anos 1990, surge uma primeira publicação sobre esse subtema na Revista (IJP, 1990), anos antes de outros dois na amostra (IJP, 1995; IJP, 1997), ambos sobre AIDS, tendo este último foco na sua prevenção (IJP, 1997). Na década seguinte, a Revista publica uma edição especial com oito artigos, uma pesquisa estudantil e uma resenha ainda sobre AIDS, dos quais, dois entraram nesta revisão: um com a comunidade latina e gay e o outro com mulheres de Porto Rico, ambos os grupos radicados nos EUA e considerados "de risco" (IJP, 2001). Preconceito e estigma contra pessoas soropositivas (mulheres, LGBTT+ e imigrantes, em especial) também foram relatados nessa amostra (IJP, 2007; IJP, 2008).

A esse respeito, Negreiros, Gomes, Colaço e Ximenes (2018, p. 28) pontuam que, à época, a categoria "risco" era considerada como de ordem sexual, enquanto "vulnerabilidade" se referia a "práticas desviantes" e certas violências. Para além dos limites dessas correlações, tais categorias não representariam a totalidade e abrangência 
das diversas categorias sociais, como "jovens", em seus respectivos contextos (Negreiros, Gomes, Colaço \& Ximenes, 2018).

Tabela 6.

Subtema Saúde sexual e (não) reprodutiva: produção de saberes e subjetividades (Tema 2)

\begin{tabular}{|c|c|c|c|c|}
\hline \multicolumn{2}{|c|}{$\begin{array}{l}\text { Revista } \\
\text { (IJP) }\end{array}$} & \multirow{2}{*}{$\begin{array}{l}\text { Pessoa(s) } \\
\text { autora(s) }\end{array}$} & \multirow{2}{*}{$\begin{array}{l}\text { Assunto(s) } \\
\text { chave }\end{array}$} & \multirow{2}{*}{$\begin{array}{l}\text { País(es) } \\
\text { participante(s) }\end{array}$} \\
\hline Ano & v. $(n)$ & & & \\
\hline 1990 & $24(1)$ & Fishbein & AIDS (teoria comportamental) & México, EUA \\
\hline 1995 & $29(2)$ & Diaz-Loving e Martinez & AIDS (grupos de risco) & México \\
\hline 1997 & $31(1)$ & $\begin{array}{c}\text { Organista, Organista, Alba G. e } \\
\text { Morán }\end{array}$ & AIDS (prevenção) & México, EUA \\
\hline 2000 & $34(1)$ & Toro-Alfonso & $\begin{array}{l}\text { AIDS (prevenção, } \\
\text { homossexualidade) }\end{array}$ & Porto Rico \\
\hline \multirow{2}{*}{2001} & \multirow{2}{*}{$35(2)$} & Ayala e Díaz & $\begin{array}{l}\text { AIDS (preconceito, } \\
\text { homossexualidade) }\end{array}$ & México \\
\hline & & León & AIDS (prevenção, políticas) & $\begin{array}{l}\text { Porto Rico, } \\
\text { EUA }\end{array}$ \\
\hline \multirow{3}{*}{2007} & \multirow[b]{2}{*}{$41(1)$} & Pecheny, Manzelli e Jones & AIDS (discriminação) & Argentina \\
\hline & & Arregui & AIDS (discriminação) & $\begin{array}{l}\text { Rep. } \\
\text { Dominicana }\end{array}$ \\
\hline & $41(2)$ & Câmara, Sarriera e Carlotto & AIDS (conduta de risco) & Brasil (BRA) \\
\hline 2008 & $42(3)$ & Torres e Faria & AIDS (homossexualidade) & Brasil (BRA) \\
\hline 2009 & $43(2)$ & $\begin{array}{c}\text { Pérez-Jiménez, Santiago-Rivas e } \\
\text { Serrano-García }\end{array}$ & $\begin{array}{l}\text { DSTs (prevenção, heteros } \\
\text { sexualidade) }\end{array}$ & Porto Rico \\
\hline \multirow{3}{*}{2010} & \multirow{2}{*}{$44(1)$} & $\begin{array}{l}\text { Hernández-Hernández e Perez- } \\
\text { Jimenez }\end{array}$ & AIDS (heterossexualidade) & Porto Rico \\
\hline & & Haack, Silva, Prati e Boeckel & $\begin{array}{l}\text { DST/AIDS (adolescência, } \\
\text { prevenção) }\end{array}$ & Brasil (BRA) \\
\hline & $44(2)$ & $\begin{array}{l}\text { Cerqueira-Santos, Calvetti, Rocha, } \\
\text { Moura, Barbosa e Hermel }\end{array}$ & AIDS (LGBTfobia, tratamento) & Brasil (BRA) \\
\hline 2012 & $46(3)$ & $\begin{array}{c}\text { Vázquez-Rivera, Nazario-Serrano e } \\
\text { Sayers-Montalvo }\end{array}$ & AIDS (LGBT, atendimento clínico) & Porto Rico \\
\hline 2016 & $50(2)$ & Cueto e Leon & $\begin{array}{l}\text { AIDS (comportamento, } \\
\text { adolescência) }\end{array}$ & Peru \\
\hline 2017 & $51(2)$ & Robles e Espinel & $\begin{array}{l}\text { AIDS (comportamento, } \\
\text { adolescência) }\end{array}$ & Equador \\
\hline 2018 & $52(3)$ & $\begin{array}{c}\text { Fonte-Boa, Queiroz, Santos e } \\
\text { Pereira }\end{array}$ & AIDS (relacionamento, cuidado) & Brasil (BRA) \\
\hline
\end{tabular}

Quase dez anos após a edição especial, novos estudos da Revista olham menos para as pessoas soropositivas e mais para o papel das políticas públicas de saúde e o impacto de suas intervenções, em especial em grupos de mulheres, LGBTT+ e imigrantes. Notaram, ainda, que o preconceito, estigma, a marginalização e exposição a diversas vulnerabilidades teriam se agravado para essas pessoas com algumas políticas em certos países (IJP, 2010; IJP, 2012). Foram prescritos, então, espaços de tratamento humanizado e sigilo, além de uma formação para os profissionais de saúde lidarem com esses públicos. 
$\mathrm{Na}$ comunidade LGBTT+, essas políticas deveriam garantir ainda acompanhamento e prevenção para suas práticas sexuais, que fogem ao padrão cisheteronormativo da saúde (no geral, estabelecido para fins reprodutivos) e instigam usos dos poderes biomédicos em "espaços absolutamente outros" (Foucault, 2009, p. 20-21). Cada território, portanto, deveria pensar estratégias e programas acolhedores, contínuos e com aporte material e financeiro para apoio, intervenção e orientação em saúde, na área de sexualidades, considerando os meandros sociais, culturais e políticos das comunidades, bem como suas subjetividades, em que há fatores não-totalizáveis ou centralizáveis no indivíduo (Guattari \& Rolnik, 1996).

Isso porque programas importados sem considerar especificidades locais por vezes não atingem positivamente a população e suas múltiplas realidades, sendo necessário adotar políticas de valorização da saúde sexual, integral e (re)produtiva que incorporem aspectos socioeconômicos, culturais e subjetivos locais, inclusive com a colaboração e participação ativa dos profissionais da saúde. Pelos artigos elencados, muitas dessas políticas já seriam buscadas nesses países, embora com clareza variável acerca de risco, vulnerabilidade (Alquati Bisol \& Tapia, 2012), entre outros conceitos, como o de saúde sexual, visto anteriormente, sendo este último bastante escasso na amostra.

\section{Família, instituição de (re)produção de relações de gênero (Tema 3)}

Neste tema, são abordadas "famílias" latino-americanas, entre outras questões. Aqui, entendemos "família" como uma instituição social, espaço privilegiado de produção de subjetividades para a manutenção e organização das sociedades.

Nos últimos anos, diversas alterações seriam observáveis nas famílias, cujos modelos estão interligados a contextos específicos, norteados por princípios sociais, culturais, políticos e econômicos (Coutinho \& Menandro, 2009; Lindinger, 2014; Roudinesco, 2003). Nesse sentido, afirmamos que as mudanças são gradativas e confrontam forças de manutenção do status quo, devendo o saber psi cuidar para não reproduzir falas hegemônicas e excludentes.

A etimologia de família (do latim, famulus, 'escravo doméstico’) remete ao poder patriarcal, arraigado nas sociedades ocidentais, bem como à religião, particularmente na América Latina, onde sua formalização e constituição foram embasadas pelo casamento religioso, que ainda norteia este espaço de interação (Zilles, 2002). 
Assim, o subtema, Representações sociais de família, agrupa sete estudos que discorreram, entre outros, sobre papéis de gênero e sexualidades nas famílias (Tabela 7). Tabela 7.

Artigos do Subtema Representações sociais de família (Tema 3)

\begin{tabular}{|c|c|c|c|c|}
\hline \multicolumn{2}{|c|}{ Revista (IJP) } & \multirow{2}{*}{$\begin{array}{l}\text { Pessoa(s) } \\
\text { autora(s) }\end{array}$} & \multirow{2}{*}{$\begin{array}{l}\text { Conceito }(\mathrm{s}) \\
\text { chave }\end{array}$} & \multirow{2}{*}{$\begin{array}{c}\text { País(es) } \\
\text { participante(s) }\end{array}$} \\
\hline Ano & v. (n) & & & \\
\hline 2006 & $40(3)$ & Toneli, Lodetti, Lucca, Gomes e Araújo & Família (paternidade, gênero) & Brasil (BRA) \\
\hline \multirow{2}{*}{2007} & $41(2)$ & Aizpurúa, Jablonski e Féres-Carneiro & Família (processo histórico) & $\begin{array}{l}\text { Brasil (BRA), } \\
\text { Argentina }\end{array}$ \\
\hline & $41(3)$ & $\begin{array}{l}\text { Medina, López-Fuentes, Valdez e } \\
\text { Jiménez }\end{array}$ & $\begin{array}{l}\text { Família (escolha do par e estereótipo } \\
\text { de gênero) }\end{array}$ & México \\
\hline 2008 & $42(1)$ & Hennigen e Guareschi & Família (estereótipo, parentalidade) & Brasil (BRA) \\
\hline 2009 & $43(1)$ & Toro e Padilla-Díaz & Família (práticas de equidade) & Porto Rico \\
\hline 2010 & $44(1)$ & $\begin{array}{l}\text { Díaz-Marroquín, Rodríguez-Ortega e } \\
\text { Flores-Angeles }\end{array}$ & Terapia familiar (gênero, poder) & México \\
\hline 2012 & $46(2)$ & $\begin{array}{l}\text { Levandowski; Barth, Munhós, Rödde e } \\
\text { Wendland }\end{array}$ & $\begin{array}{l}\text { Apoio familiar (gravidez na } \\
\text { adolescência) }\end{array}$ & Brasil (BRA) \\
\hline
\end{tabular}

A escolha de par romântico e ajuste diádico, que compareceu no Tema 1, reaparece considerando a influência dos filhos na desejabilidade social e engrandecimento conjugal de casais heterossexuais no México (IJP, 2007). Do estudo, emergiram padrões heteronormativos estereotipados, como: homens provedores de estabilidade material e afetiva; satisfação sexual como reforço de vínculo em casais; a maior "liberdade sexual" dos homens na cultura latina; e mulheres como potencialmente "boas" para gerar filhos e desempenhar cuidado.

Outros estudos do subtema focaram as relações familiares e papéis sociais (feminino e masculino), indicando mudanças nessas relações pela inserção das mulheres no mercado de trabalho formal, por demandas estruturais e macroeconômicas e pelo aumento da escolaridade feminina (IJP, 2010; IJP, 2008; IJP, 2006). Essas mudanças perpassariam a busca por relações conjugais equânimes, sobretudo nos cuidados com filhos, nos afazeres domésticos e na menor tolerância (das mulheres) com desavenças. A organização familiar também se teria alterado com o aumento significativo de casamentos informais, embora os artigos não se refiram, em regra, a orientações sexuais ou arranjos familiares que fujam da cis-heteronormatividade.

Em específico, um artigo sobre a representação midiática de pai e mãe analisou o discurso acerca de ser homem ou mulher nas concepções de gênero do Brasil e identificou concepções do feminino e masculino associadas à sexualidade, sensualidade, bem como entre feminilidade e maternidade, abordando as relações de poder (IJP, 2008). Essas relações são ainda exemplificadas por um estudo de terapia familiar feminista com um 
casal mexicano que teria dificuldades para ressiginficá-las após o homem se aposentar, dada a sua sensação de inadequação ao universo doméstico (IJP, 2010).

$\mathrm{Na}$ década anterior, então, outro artigo no eixo Brasil-Argentina reafirmou as mulheres como figuras importantes nas mudanças sociais (IJP, 2007), destacando mudanças na família relativas às Maternidades e maternagens. Nesse subtema, nove artigos abordaram o papel da mulher que gesta e se torna mãe como responsável pelo desenvolvimento e constituição de personalidade dos filhos, com critérios de análise socioeconômicos-culturais (Tabela 8).

Tabela 8.

Artigos do Subtema Maternidades e maternagens (Tema 3)

\begin{tabular}{|c|c|c|c|c|}
\hline \multicolumn{2}{|c|}{ Revista (IJP) } & \multirow{2}{*}{$\begin{array}{l}\text { Pessoa(s) } \\
\text { autora(s) }\end{array}$} & \multirow{2}{*}{$\begin{array}{l}\text { Conceito(s) } \\
\text { Chave }\end{array}$} & \multirow{2}{*}{$\begin{array}{c}\text { País(es) } \\
\text { participante(s) }\end{array}$} \\
\hline Ano & v. (n) & & & \\
\hline 1976 & $10(1 \& 2)$ & Santos e Garcia & Maternidade (atitudes, diferenças) & Brasil (BRA) \\
\hline 1989 & $23(1 \& 2)$ & Irizarry e Pacheco & $\begin{array}{l}\text { Maternidade (desenvolvimento, } \\
\text { gerações) }\end{array}$ & Porto Rico \\
\hline 1995 & $29(1)$ & $\begin{array}{l}\text { Pascual, Schulthess, Galperin e } \\
\text { Bomstein }\end{array}$ & Maternidade (parentalidade) & Argentina \\
\hline \multirow{4}{*}{2010} & \multirow{3}{*}{$44(1)$} & $\begin{array}{l}\text { Clark, Su, Kaciroti, Castillo, } \\
\text { Millan, Rule e Lozoff }\end{array}$ & Maternidade (depressão) & Chile \\
\hline & & Wendland, Maggi e Wolff & Maternidade (influência cultural) & Brasil (BRA) \\
\hline & & Moreira e Nardi & Maternidade (trabalho) & Brasil (BRA) \\
\hline & $44(3)$ & Bolsoni-Silva e Marturano & Maternidade (comportamento) & Brasil (BRA) \\
\hline 2017 & $51(1)$ & $\begin{array}{l}\text { Barragán, Romero, Campos e } \\
\text { Espinoza-Romo }\end{array}$ & $\begin{array}{l}\text { Parentalidade (estereótipo, gravidez } \\
\text { adolescente) }\end{array}$ & México \\
\hline 2018 & 52 & Brito & Maternidade (infertilidade e gênero) & EUA, México \\
\hline
\end{tabular}

Maternidade e papel materno são conceitos marcados por mudanças sociais, políticas, culturais e econômicas agregadas ao protagonismo feminino na luta por direitos e alterações na estrutura familiar (Badinter, 1985; Correia, 1998; Moura \& Araújo, 2004; Resende, 2017). A maternidade para a sociedade ocidental do final do século XVIII era considerada desejo natural da mulher, a quem cabia o papel materno e as práticas de maternagem correspondentes a investimentos psíquicos e cuidados no desenvolvimento dos filhos (Moura \& Araújo, 2004; Stellin, Monteiro, Albuquerque \& Marques, 2011). Essa imagem da mãe ideal, docilizada, foi ratificada por profissionais da saúde, pelo Estado e pela sociedade (Badinter, 1985).

Notamos nesse subtema, como no anterior, que se fala de famílias majoritariamente cis-heteronormativas, sobretudo, da relação entre maternidade e desenvolvimento dos filhos. Por exemplo, um estudo nos anos 1990 na Argentina analisou as dimensões social, didática e disciplinar da percepção de mães nos cuidados 
com os filhos, com os quais seriam afetuosas, e quanto aos maridos, vistos como mais afetuosos na região urbana que na rural (IJP, 1995).

Em 2010, pesquisadores chilenos concluíram que mães deprimidas criticariam mais os filhos, impactando seu desenvolvimento, sobretudo na primeira infância. No mesmo ano, de três artigos sobre relações maternas no Brasil, aquele sobre a relação destas com o trabalho na subjetivação de mulheres buscou transpor o debate da responsabilidade do cuidado do filho como exclusivo e natural das mulheres para o de paternidade e trabalho, pois caberia mais aos pais compartilhar essa responsabilidade que a outras mulheres da rede familiar (IJP, 2010).

Pela linha dos artigos deste subtema, foram avaliadas estratégias de regulação do comportamento/desenvolvimento infantil a partir da interação mãe-filho, por vezes avaliando ainda a percepção das mães acerca dos pais, visibilizando sua presença no cuidado com os filhos. A importância dos fatores culturais nessas relações foi marcada desde os anos 1970 (IJP, 1976), sendo que nos anos 1980 o impacto de diferenças geracionais no cuidado com os filhos é ressaltado por um artigo com mães de Porto Rico (IJP, 1989), indicando mudanças na percepção desse cuidado, mesmo ainda sob uma influência de fatores culturais tradicionais.

Recentemente, na questão da (não-)reprodução das mulheres mexicanas com histórico de infertilidade nos EUA, emergem discursos com uma cobrança social por engravidar e um receio da não-plenitude do ser mulher, mesmo com apoio dos companheiros/maridos caso não engravidassem (IJP, 2018). Questionamos, então, que certos estudos marquem o familismo e o marianismo como centrais às culturas latinoamericanas (nesta revisão, para a mexicana e a brasileira), o que pode, por vezes, apagar as diversidades culturais dessas mesmas sociedades.

Por fim, os quatro artigos do subtema Violências e famílias estudaram efeitos das lutas das mulheres no padrão de família patriarcal e nos usos dos corpos que, apesar das conquistas, continuam assujeitados a diferentes violências, como a física, psicológica e sexual, abordadas sob várias perspectivas no espaço institucional da família. Embora a violência doméstica e familiar compreenda a violência de gênero, por ação ou conduta, em espaço doméstico ou não, advindo de relação interpessoal, podendo ou não vir de parceiros íntimos (CIDH, 1994), aqui, por vezes, violência doméstica e entre parceiros íntimos serão equivalentes (Tabela 9). 
Tabela 9.

Subtema Violências e famílias (Tema 3)

\begin{tabular}{|c|c|c|c|c|}
\hline \multicolumn{2}{|c|}{ Revista (IJP) } & \multirow{2}{*}{$\begin{array}{l}\text { Pessoa(s) } \\
\text { autora(s) }\end{array}$} & \multirow{2}{*}{$\begin{array}{l}\text { Conceito(s) } \\
\text { Chave }\end{array}$} & \multirow{2}{*}{$\begin{array}{c}\text { País(es) } \\
\text { participante(s) }\end{array}$} \\
\hline Ano & v. (n) & & & \\
\hline 1994 & $28(2)$ & Flores-Ortiz, Esteban e Carrillo & $\begin{array}{l}\text { Violência familiar (contexto } \\
\text { cultural, terapia familiar) }\end{array}$ & $\begin{array}{l}\text { A. Latina } \\
\text { (vários) }\end{array}$ \\
\hline 2005 & $39(3)$ & Mena, Rodríguez e Malavé & $\begin{array}{l}\text { Violência doméstica (relações } \\
\text { afetivas e exercício de poder) }\end{array}$ & Porto Rico \\
\hline 2006 & $40(3)$ & Albarraci & $\begin{array}{l}\text { Abuso sexual infantil (protocolo } \\
\text { de intervenção) }\end{array}$ & Argentina \\
\hline 2013 & $47(1)$ & $\begin{array}{l}\text { Lourenço, Baptista, Almeida, Basílio, Koga, } \\
\text { Hashimoto, Stroppa, Bhona \& Andrade }\end{array}$ & Violências (Parceiro íntimo) & Brasil (BRA) \\
\hline
\end{tabular}

Os dois primeiros artigos identificaram o caráter estrutural da violência doméstica, pautada em relações de força e poder. Pontuaram que as intervenções para proteção, cuidado e fortalecimento das vítimas devem considerar fatores étnicos-culturais, sem revitimá-las, dado o desafio de romper o ciclo da violência que, em regra, afasta o agressor e assim rompe com laços familiares que seriam, então, caros às culturas latinoamericanas (IJP, 1994; IJP, 2005).

Por último, um artigo propõe um protocolo de atendimento que auxilie a identificar abuso sexual em crianças, pensando em proteção e intervenção (IJP, 2006). Outro, a partir de revisão no Brasil, identificou pouca produção com vistas à prevenção da violência de parceiro íntimo, importante para pensar as políticas públicas de saúde (IJP, 2013).

Neste tema, portanto, dos vinte artigos reunidos, o foco na família tradicional ainda predomina, o que indica formas de controle por usos apenas dos conceitos já legitimados por discursos científicos. Notamos que o estudo dessa instituição pela Psicologia trouxe para si um espaço de saber que, por vezes, colaborou com o status quo de cada época (Silva, 2016).

Dessa forma, com as lutas no século XIX pela laicização de Estados e pelo casamento civil, a família paulatinamente se adequou às novas realidades das múltiplas possibilidades de arranjos que não se afirmam na concepção cis-heteronormativa desta instituição (Oliven, 2019). Por vezes, em nome das subjetividades dominantes, temas relativos à sexualidade, ao casamento e à assimetria de poderes e direitos, no âmbito "intelectual, profissional e sexual da mulher", são discutidos entre profissionais da área "psi" em função da neutralidade científica e perpetuados em suas práticas como normas (Coimbra, 1995, p. 36-37). 
Já no século XX, Silva (2016, p. 78) aponta que expressões de gênero e sexualidades consideradas "subversivas" foram objeto de vigilância, denúncia e punição moral na ditadura civil-militar brasileira. Assim como o estudo das famílias demonstrava um viés para fins de manutenção da estrutura político-social-ideológica, a repressão ditatorial na região impactou na produção da época, seja pela censura dos debates, seja pela perseguição aos saberes relativos a temas que escapavam a modos hegemônicos da repressão, como os deste trabalho.

\section{Considerações Finais}

Embora não tenha sido objetivo deste trabalho generalizar resultados para a totalidade da produção latino-americana sobre os temas abordados, esperamos que a presente revisão auxilie na compreensão da constituição desses conceitos em Psicologia na região, bem como do esforço na construção de estratégias teóricas e metodológicas para seu estudo, mais próximas à sua realidade psicossocial, ética e cultural.

Nesse processo, tiveram um papel central, como indicado no primeiro tema, as discussões sobre "diferenças sexuais" e "papéis sexuais" que declinam a partir de 1990, em especial, após 2000. O declínio desse debate, portanto, coincide com a crescente produção em torno de "gênero" e das "sexualidades" não-heteronormativas.

Esse aumento contou com significativa produção nas áreas relacionadas à saúde, como visto no segundo tema, em que foi possível identificar que expressão subjetiva da existência e a somatização dos sofrimentos possuem correlação. Por conseguinte, a forma de manifestar o adoecimento traria a necessidade de atendimentos diferenciados a grupos em seus contextos socioeconômico-político e culturais específicos, sendo evidente a importância de estratégias de intervenção em saúde, saúde sexual e (não-)reprodutiva, genuínas às realidades locais.

Na constituição desse debate, destacamos, no terceiro tema, a predominância da reprodução de conceitos hegemônicos das relações familiares e dos papéis sociais de gênero (feminino e masculino) no exercício da maternidade e no desenvolvimento dos filhos. Nesse sentido, apesar de produções recentes indicarem mudanças na família pela inserção da mulher no mercado de trabalho, pelo aumento de sua escolaridade e dos relacionamentos informais, faltaram estudos sobre modos familiares que não se afirmam na cis-heteronormatividade.

No geral, portanto, as limitações apontadas por esta revisão, principalmente no que se refere ao escopo altamente cis-heteronormativo dos artigos listados, mesmo que 
não reflitam a posição oficial da SIP, podem indicar linhas gerais das múltiplas produções latino-americanas sobre esses temas. Isto sugere a importância de produções acadêmicas, na área da Psicologia, atentas às realidades e intersecções que marcam as vivências dos povos da América Latina. 


\section{Referências}

Alquati Bisol, C., \& Tapia, A. M. (2012). A Psicologia e o conceito de risco: estudos publicados entre 1999 e 2010. Psico, 43(3).

https://revistaseletronicas.pucrs.br/ ojs/index.php/revistapsico/article/view/7824

Angelini, A. L. (2012). O papel da Sociedade Interamericana de Psicologia no desenvolvimento da Psicologia na América Latina. Interamerican Journal of Psychology, 46(1), 9-20.

https://www.redalyc.org/articulo.oa?id=284/28424858002

Andrade, D. S. V. \& Santos, H. M. (Orgs.) (2013). Gênero na Psicologia: Articulações e Discussões. Salvador: CRP-03. www.crp03.org.br/wpcontent/uploads/2015/08/ Genero-na-Psicologia-articulacoes-e-discussoes.pdf

Antunes, M. A. M. (2012). A Psicologia no Brasil: um ensaio sobre suas contradições. Psicologia: Ciência e Profissão, 32(spe), 44-65. https://dx.doi.org/10.1590/S1414-98932012000500005

Badinter, E. (1985). Um Amor conquistado: o mito do amor materno. Nova Fronteira.

Borges, L. S.; Canuto, A. de A. A.; Oliveira, D. P. de, \& Vaz, R. P. (2013). Abordagens de gênero e sexualidade na Psicologia: revendo conceitos, repensando práticas. Psicologia: Ciência e Profissão, 33(3), 730-745. https://dx.doi.org/10.1590/S1414-98932013000300016

Braun, V., \& Clarke, V. (2006). Using thematic analysis in psychology. Qualitative Research in Psychology, 3 (2).77-101. http://dx.doi.org/10.1191/1478088706qp063oa

Butler, J. (2013). Problemas de gênero: feminismo e subversão de identidade. Civilização Brasileira.

Campos, I. de O., \& Zanello, V. (2016). Saúde mental e gênero: o sofrimento psíquico e a invisibilidade das violências. Vivência: Revista De Antropologia, 1(48), 105-117. https://periodicos.ufrn.br/vivencia/article/view/11505

Coimbra, C. (1995). Guardiães da ordem: Uma viagem pelas práticas psi no Brasil do "Milagre". Oficina do Autor.

Connell, R. W. (1995). Masculinities. University of California Press.

Correia, M. de J. (1998). Sobre a maternidade. Análise Psicológica, 16(3), 365-371. http://www.scielo.mec.pt/pdf/aps/v16n3/v16n3a02.pdf

Corte Interamericana de Direitos Humanos - CIDH (1994). Convenção Interamericana para prevenir, punir e erradicar a violência contra a mulher. Belém do Pará, Brasil. http://www.cidh.org/Basicos/Portugues/m.Belem.do.Para.htm

Coutinho, S.M.S., \& Menandro, P.R.M. (2009). A Dona de Tudo: um estudo intergeracional sobre representações sociais de mãe e esposa. PPGP/UFES/Facastelo/GM Ed.

Costa, A.B.; Zoltowski, A.P.C. (2014). Como escrever um artigo de revisão sistemática. S. H. Koller; M. C. P. P. Couto \& J. V. Hohendorff. Manual de Produção Científica. Penso.

Foucault, M. (1982). História da loucura. Perspectiva.

Foucault, M. (1985). História da sexualidade I: a vontade de saber. Graal.

Foucault, M. (2001). Microfísica do poder. Graal.

Foucault, M. (2009). O corpo utópico, as heterotopias. N-1 edições.

Guattari, F. \& Rolnik, S. (1996). Micropolítica: cartografias do desejo. Vozes. 
Gomes, R.; Murta, D; Facchini, R; \& Meneghel, S. N. (2018). Gênero, direitos sexuais e suas implicações na saúde. Ciência e Saúde Coletiva, 23(6), 19972005. https://doi.org/10.1590/1413-81232018236.04872018

Hur, D.U., \& Lacerda Júnior, F. (2017). Ditadura e insurgência na América Latina: psicologia da libertação e resistência armada. Psicologia: Ciência e Profissão, 37(spe), 28-43. https://doi.org/10.1590/1982-10.1590/19823703020002017

Lindinger, L. (2014). Violação de direitos e medidas protetivas na concepção de juízes que atuam em Juizados de Infância e Juventude (Dissertação). UFES, Vitória, ES.

Maluf, M. (2004). A Participação de Psicólogos Brasileiros na Sociedade Interamericana de Psicologia: Contribuições e Perspectivas. Interamerican Journal of Psychology, 38 (2), 323-332. https://www.redalyc.org/articulo.oa?id=284/28438219

Medeiros, P. F. de, Bernardes, A. G., \& Guareschi, N. M. F. (2005). O conceito de saúde e suas implicações nas práticas psicológicas. Psicologia: Teoria e Pesquisa, 21(3), 263-269. https://doi.org/10.1590/S0102$\underline{37722005000300002}$

Medrado, B., \& Lyra, J. (2008). Por uma matriz feminista de gênero para os estudos sobre homens e masculinidades. Revista Estudos feministas, 16, 20-35. https://periodicos.ufsc.br/index.php/ref/article/view/S0104026X2008000300005/9130

Medrado, B., \& Lyra, J. (2012). O gênero dos/nos homens: linhas de uma protogenealogia. Ciência \& Saúde Coletiva, 17(10), 2579-2581. https://dx.doi.org/10.1590/S1413-81232012001000003

Moura, S. M. S. R. de, \& Araújo, M. de F. (2004). A maternidade na história e a história dos cuidados maternos. Psicologia: Ciência e Profissão, 24(1), 4455. https://dx.doi.org/10.1590/S1414-98932004000100006

Negreiros, D. J., Gomes, I. D., Colaço, V. de F. R., \& Ximenes, V. M. (2018). Risco e vulnerabilidade: pontos de convergência na produção brasileira sobre juventudes. Desidades, (18), 20-33. http://pepsic.bvsalud.org/pdf/desi/n18/n18a03.pdf

Nogueira, C. (2001). Feminismo e discurso do gênero na Psicologia social. Psicologia \& Sociedade, 3 (1), 1-28 [online]. http://hdl.handle.net/1822/4117

Oliven, L. R. A. (2019). A autonomia de separação de direito. Revista Interdisciplinar de Direito, 17 (2), 169-184.

Organização Mundial da Saúde - OMS (2006). Defining sexual health: Report of a technical consultation on sexual health. Geneva. www.who.int/ reproductivehealth/publications/sexual_health/defining_sexual_health.pdf

Paula, T. R., Porto, E. J., \& Carvalho, C. S. (2019). Um sobrevoo pelo estado da arte sobre gênero e sexualidade na pesquisa. Psicologia: Ciência e Profissão, 39 (n.spe 3), 194-205. https://doi.org/10.1590/1982-3703003228573

Paiva, V. (2008). A psicologia redescobrirá a sexualidade? Psicologia em Estudo, 13(4), 641-651. https://dx.doi.org/10.1590/S1413-73722008000400002

Polanco, F. (2016). Impacto y evolución del conductismo en la Revista Interamericana de Psicología y la Revista Latinoamericana de Psicología: Un análisis socio- bibliométrico (1969-2008). Tese de Doutorado (unpublished). Universidad Nacional de San Luis, San Luis, Argentina. 
Rago, M. (1998). Descobrindo historicamente o gênero. Cadernos Pagu, (11), 89-98. https://periodicos.sbu.unicamp.br/ojs/index.php/cadpagu/article/view/863446 $\underline{5}$

Resende, D. K. (2017). Maternidade: Uma Construção Histórica e Social. Pretexto Revista da Graduação em Psicologia da PUC-MG, 2(4), 175-191. http://periodicos.pucminas.br/index.php/pretextos/article/view/15251

Roudinesco, E. (2003). A família em desordem. Zahar.

Saffioti, H. I. B. (2001). Contribuições feministas para o estudo da violência de gênero. Cadernos Pagu, (16), 115-136. https://doi.org/10.1590/S010483332001000100007

Scarparo, H. B. K., Torres, S., \& Ecker, D. D. (2014). Psicologia e ditadura civilmilitar: reflexões sobre práticas psicológicas frente às violências de estado. EPOS, 5(1), 57-78. http://pepsic.bvsalud.org/pdf/epos/v5n1/04.pdf

Scott, J. W. (1995). Gênero: uma categoria útil para análise histórica. Educação \& Realidade, 20(2), 71-99. https://seer.ufrgs.br/index.php/educacaoerealidade/article/view/71721

Silva, N. de F. (2016). Ditadura civil-militar no Brasil e a ordem de gênero: masculinidades e feminilidades vigiadas. Mosaico, 7(11), 64-83. doi:http://dx.doi.org/10.12660/rm.v7n11.2016.64778

Strey, M. N. (2004). Violência de gênero: uma questão complexa e interminável. M. Strey; M. Azambuja \& F. Jaeger. (Orgs.). Violência, gênero e políticas públicas, 13-43. EDIPUCRS.

Souza, M. F. de. (2009). As análises de gênero e a formação do campo de estudos sobre a(s) masculinidade(s). Mediações, 14(2), 123-144. http://dx.doi.org/10.5433/2176-6665.2009v14n2p123

Souza, L. G. S. (2012). Profissionais de saúde da família e representações sociais de alcoolismo. (Tese de Doutorado). Pós-Graduação em Psicologia: UFES. Vitória, Brasil

Stellin, R. M. R., Monteiro, C. F. d'A., Albuquerque, R. A., \& Marques, C. M. X. C. (2011). Processos de construção de maternagem. Feminilidade e maternagem: recursos psíquicos para o exercício da maternagem em suas singularidades. Estilos da Clínica, 16(1), 170-185. http://pepsic.bvsalud.org/pdf/estic/v16n1/a10v16n1.pdf

Torres Fernandez, I., Polanco, F., Pereira, S., Sueli Beria, J. \& Zapico, M. (2017). Celebrating 50 years of the Interamerican Journal of Psychology: a content analysis. Interamerican Journal of Psychology, 51 (3), 320-334. https://doi.org/10.30849/rip/ijp.v51i3.954

Zanello, V.; \& Bukowitz, B. (2011). Loucura e cultura: uma escuta das relações de gênero nas falas de pacientes psiquiatrizados. Revista Labrys Estudos Feministas. 20-21. http://www.labrys.net.br/labrys20/brasil/valeska.htm

Zilles, U. (2002). Apresentação. In: A. Wagner. (Org.). Família em cena: tramas, dramas e transformações (9-11). Vozes. 